\title{
Using Social Networks to Sample Migrants and Study the Complexity of Contemporary Immigration: An Evaluation Study
}

\author{
M. Giovanna Merli \\ Sanford School of Public Policy and Duke Population Research Institute, Duke University \\ giovanna.merli@duke.edu
}

Ted Mouw

Department of Sociology and Carolina Population Center, University of North Carolina, Chapel Hill tedmouw@email.unc.edu

Claire Le Barbenchon

Sanford School of Public Policy and Duke Population Research Institute, Duke University claire.lebarbenchon@duke.edu

Allison Stolte

Department of Sociology and Duke Population Research Institute, Duke University

allison.stolte@duke.edu

RUNNING HEAD: Sampling Migrants from their Social Networks

Acknowledgements: The data collection described here were made possible by an NICHD Grant R21HD086738 to Duke University and the University of North Carolina (Merli and Mouw MPI) with additional support for a pilot study to Merli via the Duke Population Research Center, NICHD Grant P2CHD065563. We thank Francesca Florey-Eischen for expert project management, our excellent field interviewers Chunyu Xiao, Jun Xing, Hui Yan, and Nan Zhou for their enthusiasm and hard work and Sara Curran, Emilio Parrado, Herb Smith, Ashton Verdery and four anonymous reviewers for constructive comments. 


\begin{abstract}
We test the effectiveness of a link-tracing sampling approach, Network Sampling with Memory (NSM) to recruit samples of rare immigrant populations with an application among Chinese immigrants in the Raleigh-Durham Area of North Carolina. NSM uses the population network revealed by data from the survey to improve the efficiency of link-tracing sampling, and has been shown to substantially reduce design effects in simulated sampling. Our goals are: (1) to show that it is possible to recruit a probability sample of a locally rare immigrant group using NSM and achieve high response rates; (2) to demonstrate feasibility of collection and benefits of new forms of network data that transcend kinship networks in existing surveys and can address unresolved questions about the role of social networks in migration decisions, the maintenance of transnationalism, and the process of social incorporation; (3) to test the accuracy of the NSM approach to recruit immigrant samples by comparison with the American Community Survey (ACS). Our results indicate feasibility, high performance, cost-effectiveness and accuracy of the NSM approach to sample immigrants for studies of local immigrant communities. This approach can also be extended to recruit multi-site samples of immigrants at origin and destination.
\end{abstract}

Keywords: Immigration, Migration, Social Networks, Survey Sampling 


\section{Introduction}

Demographers have long relied on, and been key drivers of, innovations in survey methods that facilitate research into core demographic concepts (e.g., the World Fertility Surveys). The study of migration is no exception (e.g., The Mexican Migration Project). In recent years specialized regional surveys dedicated to understanding migration have generated new evidence, study designs and measurement techniques (e.g., the Latin American Migration Project, LAMP; the Migration from Africa to Europe, MAFE; the Mexican Family Life Survey, MxFLS; the NIDIEurostat Push-Pulls International Migration project). These efforts complement attempts to measure migration in population-monitoring surveys like the American Community Survey (ACS), in administrative, commercial, or other novel data sources (Caballero, Cadena, and Kovak 2018; Cesare et al. 2018), or through ethnographic or in-depth interview-based studies of migrant communities (Hagan 1998; Lee and Zhou 2015; Mountz and Wright 1996; Parrado, McQuiston and Flippen 2005).

In the United States, changes in the profile of immigrants and their spatial distribution have only increased the importance of these multifaceted attempts, but they also raise new challenges for researchers interested in migration and its dynamics. Immigrants in the U.S. are increasingly heterogeneous in terms of their origins and demographic profile. Among recent cohorts, Asian immigrants outnumber Mexican immigrants, with immigration from China and India topping Asian immigration (Pew Research Center 2020). Immigration trends from Central America (Pew Research Center 2017) and Africa (Elo et al. 2015) further increase the complexity of immigration. Within migrant sending countries, there is increasing heterogeneity in subnational areas of origin, with more regions sending large numbers of migrants to the United States and compositional shifts in the urban-rural gradient of migrant sending 
communities (Liang and Morooka 2004; Riosmena and Massey 2012). Recent cohorts of Mexican immigrants are also more likely to work outside of agriculture (Garip 2012, 2016), while more than half of Asian immigrants who arrive as adults have at least a bachelor's degree (Pew Research Center 2013). This heterogeneity strongly suggests the need to collect sufficiently large samples by country of origin rather than simply relying on overly broad race and panethnic categories such as "Asian" or "Hispanic".

Additionally, immigrants in the U.S. are increasingly dispersed: more live in suburban areas (Lee and Kye 2016; NAS, 2015), new destination areas (Flippen and Kim 2015; Sakamoto, Kim, and Takei 2013), and fewer are concentrated in ethnic neighborhoods in the largest cities of traditional gateway areas of California, Texas, Illinois, and the Northeast. These new patterns of residential settlement reduce segregation within metro areas and across regions with important implications for our understanding of immigrant incorporation and the role of social networks in this process (NAS 2015). The spatial dispersion of immigrants also implies that the foreign-born represent smaller proportions of local populations, making sampling rare immigrant population groups with conventional place-based household sampling strategies more challenging and costly. This limits demographers' ability to study specific immigrant groups in new destinations, where rapidly growing local immigrant communities remain understudied (Parrado, McQuiston and Flippen 2005). Compounding these concerns are high non-response and non-interview rates in contexts of harsh immigration policy climates, especially those requiring legal documentation (Van Hook et al. 2014).

While growing heterogeneity of immigrants and their migration experiences motivates the need for new approaches to collecting information, evidentiary gaps in the understanding of fundamental migration processes such as the decision to migrate or long-term dynamics of social 
and economic incorporation have required a broad range of research designs that include longitudinal and multi-sited perspectives. These approaches capture the process of migration, enable the analyses of the linkages between origins and destinations in a migration system as well as the comparison of movers and stayers (Beauchemin 2014; Billsborrow 2016; Fawcett and Arnold 1987). Along with these advances have been critical efforts to document migrant networks. Migrant networks are an important part of the meso-level social structure that connects migrants at destination to individuals at origin and fosters more migration (Boyd 1989; de Haas 2010; Massey 1990). Although there is agreement that migration is a network-related social process (Bashi 2007; Garip and Asad 2016) and that migrants create transnational social fields that connect origin and destination through their activities and relationships (Levitt and Glick Schiller 2004; Lubbers, Verdery, and Molina 2020; Waldinger 2013), the measurement of social networks relevant to migration and the reliance on networks to recruit population representative samples of migrants have not been a privileged domain in traditional surveys of migration.

This paper illustrates the application of a new network sampling methodology for use in the study of migration, Network Sampling with Memory (NSM, Mouw and Verdery 2012: Merli et al. 2016) and an associated network data collection protocol that relies on migrants' social networks to efficiently recruit samples of rare populations of migrants, and can be extended to the recruitment of multi-sited samples. The approach incorporates a network-based probability sampling framework, a peer referral process that encourages survey participation, and an efficient and cost-effective sample recruitment strategy that reduces the screening costs 
associated with sampling rare populations. ${ }^{1}$ An additional benefit of this approach is the collection of social network data that can improve the understanding of the mechanisms shaping migration decisions and preserving co-ethnic ties across interconnected local, origin, and global networks.

Here we describe the application of this method to sample a local immigrant community in a U.S. destination recruited for the Chinese Immigrants in the Raleigh-Durham Area (ChIRDU) Study. We evaluate NSM performance in terms of the feasibility and practicality of recruiting network-based samples and collecting the required network data within a survey instrument that focuses on the experiences of migration and immigration. We illustrate the potential of the ancillary network data to investigate immigrant incorporation and transnationalism and the utility of these data to assess the role of peer referral embedded in the network sampling design in achieving high response rates. To assess the accuracy of the sampling method, we compare the characteristics of the ChIRDU sample recruited with NSM techniques with those of the ACS. We conclude with a discussion of the power of this linktracing approach and the associated network data collection for studying migration in the $21^{\text {st }}$ century.

${ }^{1}$ This point is best illustrated by an example. Consider the Immigrant and Intergenerational Mobility in Metropolitan Los Angeles (IIMMLA) survey which collected data from a sample of 2,822 first and second generation immigrants. Participants were screened with random digit dialing (RDD) which reportedly required dialing 263,783 telephone numbers in order to recruit 10,893 potential respondents (Rumbaut, Massey, and Bean 2006:450). This suggests high monetary and time costs required to recruit an immigrant sample even in an immigrant destination community as large as Los Angeles. Furthermore, the IIMMLA collected data on all immigrant groups in LA, which suggests that, if a researcher wished to focus on a single origin group, the relative number of screening interviews would be even larger. 


\section{Networks and Migration}

A migrant network perspective is rooted in the original concept of chain migration, whereby the decision to migrate is a function of a potential migrant's individual characteristics and a broader system of social linkages between migrants and non-migrants connecting origin and destination (Boyd 1989, MacDonald and MacDonald 1964). Migration researchers have noted that friends and relatives are key sources of information, assistance, and motivation that affect individuals' propensity to migrate (Boyd 1989; Curran et al. 2005; Dolfin and Genicot 2010; de Haas 2010; MacDonald and MacDonald 1964; Massey et al. 1993; Munshi 2020; Palloni et al. 2001; Tilly and Brown 1967). Scholars also argue that social network dynamics play a central role in migrants' social and economic incorporation in their host societies (Lancee 2012; Nee, Sanders, and Sernau 1994; Ryan et al. 2008), and that the corresponding set of ties connecting migrants to their origin communities is an important indicator of transnationalism (Haug 2008; Levitt and Glick Schiller 2004; Lubbers, Verdery and Molina 2020). Nonetheless, a recurring challenge in studying the role of networks in migration is the need to collect high-quality network data that measure variably meaningful links between migrants, potential migrants, and non-migrants in origin and destination communities (Boyd 1989; Fawcett 1989; Haug 2008; Lubbers, Vedery and Molina 2020).

Several large community-based demographic studies such as the Mexican Migration Project (MMP Fussell and Massey 2004; Massey et al. 1987), the Latin American Migration Project (LAMP, Donato et al. 2010), the Nan Rong Project (Jampaklay, Korinek, and Entwisle 2007; Korinek, Entwisle, and Jampaklay 2005), and the Migration between African and Europe Project (MAFE, Beauchemin 2015, 2018) have contributed substantially to the collection and analyses of data on networks and migration. The strength of these studies lies in their use of 
survey methods to capture individual migration histories with which to compute retrospective measures of social networks connecting kin, as well as shared households and communities, in sending and receiving locations. As a significant innovation, the MAFE and Nanrong projects also collected data on egocentric personal networks connecting migrant respondents to friends and kin at origin using name generators motivated by specific migration-related questions and, in the Nanrong case, augmented by a longitudinal study design (Rindfuss et al. 2004).

Although not exhaustive of the empirical results of the MMP, LAMP, Nan Rong, and MAFE projects, a useful illustration of the progress made by these projects is their advancement of the empirical evidence in support of the theory of "cumulative causation" in migration (Massey and Espinosa 1997; Massey and García-España 1987; Taylor 1986, 1987; Baizan and Gonzalez-Ferrer 2016; Côté et al. 2015; Durand, Massey, and Zenteno 2001; Fussell and Massey 2004; Garip and Asad 2016; Massey and García-España 1987; Massey and Zenteno 1999; Palloni et al. 2001; Toma 2016), which explains how migration emerges, builds momentum and is sustained through the network-based institutions that facilitate the flow of resources and information about destination opportunities, reduce the risks and costs of migration, and fuel imagination about the possibilities of migration (Massey 1988; Massey, Arango, et al. 1994).

Nonetheless, despite considerable progress in understanding the role of networks in migration, substantial questions remain. De Haas (2010) suggests that the existing literature on cumulative causation neglects the contingent nature of networks which depend crucially on the willingness of network members to help. He argues that this explains why only some pioneer migrants initiate a network-driven system of self-sustaining migration flows (e.g., MacDonald and MacDonald 1964) and why well-established migration systems decline over time as destination communities become disengaged from ties and connections with the origin. Echoing 
the contingent nature of network effects, others have argued that migration networks should not be thought of as an "undifferentiated resource" but, instead, as structured by the labor demand of employers (Krissman 2005) or reflecting fundamental regional, class, and gender differences (Curran et al. 2005; Curran and Rivero-Fuentes 2003; Guarnizo, Sanchez, and Roach 1999; Toma and Vause 2014). Yet others have stressed the importance of a better understanding of the mechanisms behind network effects (Dolfin and Genicot 2010; Garip and Asad 2016), noting the "downside" of social capital caused by the ways in which network ties can be exclusionary and exploitative (Gold 2005; de Haas 2010; Hill 2018; Hoang 2015; Menjivar 2000; Portes 1998). Finally, researchers have called attention to the fact that migrants may need to reconstruct their networks, because the disruptive act of migration can change the composition of networks postmigration (Lubbers et al. 2010; Ryan 2011) and constrain migrant's social capital resources (Lee 2015).

Some of these critiques reflect how the limited collection of social network data has constrained demographers' understanding of the heterogeneous role of social networks in migration. Although previous research has focused on the types and nature of migrants' networks that fuel migration behaviors (Curran et al. 2005; Curran and Rivero-Fuentes 2003; Davis, Stecklov, and Winter 2002; Palloni et al. 2001), the literature is dominated by proxy measures of migrant networks. Social ties to previous migrants have been operationalized through aggregate measures of migrant prevalence in the sending community (e.g., Taylor, Rozelle, and de Brauw 2003; Massey and Aysa-Lastra 2011; Massey, Goldring, and Durand 1994; Zhao 2003), or counts in household rosters that miss other relevant social contexts (e.g. friends, family, colleagues, etc.) (Palloni et al. 2001). Similarly, proxy measures are often used to determine tie strength: village members as weak ties, and family or household members as strong ties (Garip 
2008), or blood proximity or generation of family tie to determine strong ties while attributing weaker ties to friendships (Liu 2013). Absent from most migration surveys are aspects of social ties salient for shaping migration decisions, such as strength (amount of time spent together, level of closeness, frequency of communication), type of interaction (mutual confiding, help and services rendered) and flow (resources or information shared). Reflecting on the limitations of existing data, Haug (2008, p.600) argues that "what is lacking is an elaborated method to collect data on social networks of migrants at relatively low cost in order to be able to investigate network structures in migration contexts."

A fuller understanding of how migrant networks shape migration and incorporation requires more granular network data. Lubbers et al. (2010) and Vacca et al. (2020) illustrate the benefits of detailed network data on migration, as they collect small-scale surveys of personal networks with up to $45 \mathrm{kin}$ and friend contacts per respondent, which enables a sophisticated analysis of the temporal dynamics of network change and the impact of features of the network structure of immigrants (e.g. density, composition, network position) on their social incorporation. Although larger surveys must consider a trade-off between the costs, in terms of time, respondent burden and non-response, involved in the elicitation of a large number of network contacts and the amount of information sought per contact, these studies suggests that it is possible to collect network data that goes beyond the kinship networks available in the main demographic migration studies (Lubbers, Verdery an Molina 2020). In the following section we consider methods of data collection that support the collection of migrant network data while allowing for a cost-effective and efficient collection of representative samples of rare populations of migrants. 


\section{Link-tracing Designs for the Recruitment of Migrant Samples -- Network Sampling with Memory}

Link-tracing designs, where referrals from previous respondents are the source of new respondents, hold several advantages for the study of migration and immigration experiences. They reduce the confidentiality concerns with survey participation because potential respondents are reached through their social networks and may be more likely to participate if there is evidence of a friend complying with a similar request. Peer referral as a vehicle for community penetration of a survey may be particularly important in reaching hard-to-survey and hidden populations such as undocumented migrants because it can increase the survey credibility and willingness to participate among those with a lower propensity to participate in conventional surveys where the first point of contact is an unknown researcher.

Samples recruited with link-tracing designs, often referred to as snowball and chain referral samples, are generally regarded as convenience samples because of the absence of a sampling frame and the lack of a probability-based sampling strategy (Biernacki and Waldorf 1981; Sudman and Kalton 1986). Although such methods have important uses in qualitative research, allowing for "case study logic" rather than "sampling logic" (Small 2009), they are likely to run afoul of orthodox demographic sensibilities that demand generalization from samples to populations. Respondent Driven Sampling (“RDS” Heckathorn 1997, 2002) has sought to make chain referral sampling more generalizable by tracing the links in the underlying social network of the population of interest and proposing an inference strategy for estimating population parameters of hidden populations (Salganik and Heckathorn 2004; Volz and Heckathorn 2008) which relies on assumptions about the network structure and the peer-driven process of sample recruitment over the network. When these assumptions are not met, 
evaluations of RDS have found that its estimates may be far from population parameters and that RDS estimators exhibit large sampling variance in mean estimates and large design effects. ${ }^{2}$

Network Sampling with Memory ("NSM” Mouw and Verdery 2012) improves over RDS in that it directly collects detailed network information as part of the survey through multiple waves of respondents' nominations, referral and recruitment of new respondents, to improve the sampling efficiency and precision of link-tracing designs. Sample recruitment starts with the identification of a limited number of initial respondents (“seeds") known to the researcher. Seeds and subsequent waves of respondents are asked to nominate their social contacts who are members of the population of interest (referred to in the social network literature as "alters") by providing minimally identifying information. The amount and type of minimally identifying information sought from respondents about their alters can be determined following formative research with members of the population of interest and may include initials of surnames, full first names, last four digit of cell phone number or any other sufficiently detailed information. Unlike RDS, where the selection and recruitment of the next wave of respondents is done by peers, in NSM the sampling process is controlled by researchers. Respondents are asked to refer (i.e. provide contact information) their nominated alters to the researcher, who will select a subset and contact them for a survey interview.

NSM uses the information provided by respondents about their nominated alters (nodes in the network) to reveal the network, and a sampling algorithm to determine whom, from the

\footnotetext{
${ }^{2}$ Evaluations of the statistical performance of RDS (point estimates and variance) include simulation studies on simulated networks (Gile and Handcock 2010) or on previously mapped realistic networks (Goel and Salganik 2010, Mouw and Verdery 2012) and empirical evaluations of RDS in real-world hidden populations including comparisons with populations with known characteristics (McCreesh et al. 2012; Merli et al. 2015; Verdery et al. 2015; Wejnert 2009; Yamanis et al. 2013).
} 
current list of everyone who has been nominated in the survey, should be contacted for a survey interview. The algorithm directs the sampling process to spread through the network by placing higher sampling probability on nodes that have been nominated less frequently by previously sampled respondents. NSM seeks to balance two competing interests: finding all the members of the social network and sampling from the social network in a way that yields representative insights. As the sampling progresses, the reconstructed network mapped from the minimally identifying information on nominated alters increasingly resembles the true network linking members of the target population. More information on the NSM sampling process can be found in Section 1 of the Appendix.

NSM's statistical performance was evaluated with simulations yielding the following results: First, in simulated sampling based on known networks from Add Health and Facebook, NSM reduces design effects by $98.5 \%$ relative to RDS, along with asymptotically unbiased population estimates (Mouw and Verdery 2012), which means that, at a given sample size, one can achieve the same or better statistical precision (and, consequently, narrower confidence intervals) using NSM. Because design effects are a function of sample size, these results also imply that researchers using NSM need only collect samples in the hundreds rather than in the thousands as would be required by RDS for similarly precise and accurate estimates (Goel and Salganik 2010; Mouw and Verdery 2012; Spiller et al. 2018; Wejnert et al. 2012). Second, NSM is practical, as the number of nominations and referrals required is not large. Mouw et al. (2014) showed with simulations using the largest Add Health network, that collecting at least 6 nominations and 3 referrals per sample respondent does not compromise NSM's sample precision, only slightly reducing sampling efficiency relative to simple random sampling. 
Finally, NSM has another advantage: it collects explicit social network data that can be concurrently used to test hypotheses about substantive migration topics (e.g. Merli et al. 2016).

But while simulated sampling is useful to test the statistical properties of NSM relative to other sampling approaches, less is known about how this approach performs in the field. In what follows, we evaluate the first complete field application of NSM and its data collection protocol.

\section{The Context: Chinese immigrants in the Raleigh-Durham Area of North Carolina}

Asian immigrants are dispersing across a large number of new destinations in the U.S. In particular, the American South is experiencing some of the fastest immigrant growth rates, but lacks established co-ethnic settlements typical of immigration gateways and other more traditional immigrant destinations (Flippen and Kim 2015). In North Carolina, Asians are now the fastest growing population group in the state, with a documented increase of $5.1 \%$ between 2016 and 2017 (Tippett 2018). Compared to white natives, Asian immigrants in the South have higher levels of education and hourly wages, contrary to the negative Asian-Whites wage difference observed in other U.S. regions. Compared with Asian immigrants in other U.S. regions, they have higher levels of education, hourly wages, and employment in professional and technical occupations (Sakamoto, Kim, \& Takei 2013). The Raleigh-Durham area of North Carolina, which comprises Orange, Durham and Wake counties, is home to three major universities, large university health systems as well as many IT and pharmaceutical companies, and a rapidly growing population of Chinese and Indian immigrants over the last two decades (Tippett 2018). However, despite this rapid growth, Chinese immigrants still only account for $1 \%$ of the area residents, which, together with their spatial dispersion, poses challenges for the recruitment of sufficiently large samples using conventional probability sampling techniques. 
Moreover, Chinese immigrants in the Raleigh-Durham area provide an ideal population to evaluate the accuracy of NSM samples by comparison with the ACS, because, as a highly educated population, they are more likely to be adequately covered by the ACS.

\section{The Chinese Immigrants in the Raleigh-Durham Area (ChIRDU) Study: Sample, Survey and Data}

The ChIRDU Study was conducted between March 2018 and January 2019. Eligibility for participation included being born in mainland China, Taiwan or Hong Kong, age 18 and older, and current resident in Durham, Orange or Wake counties. Individuals on long-term temporary visas such as international students were not eligible to participate. Sampled respondents who agreed to participate were interviewed with one of three modes of data collection: in-person, phone and web. ${ }^{3}$ A sample size of 200 respondents per mode was deemed sufficiently large to detect significant differences between key demographic characteristics of the NSM samples and those of a comparable ACS sample. Appendix Section 2 describes sample size calculations. The study underwent ethical review by the IRBs of Duke University and the University of North Carolina, Chapel Hill.

The in-person and phone arms of the study were launched first, in March 2018. Interviews were conducted in Chinese or English (depending on respondent's preference) by four bilingual field interviewers who were independently recruited from the Raleigh-Durham area and

\footnotetext{
${ }^{3}$ Although prior work suggests lower costs, response rates, and representativeness of web surveys (Dillman, Smyth, and Christian 2009), evidence of the success of web-based network sampling among the general population is limited to one internet-based RDS study (Schonlau and Kapteyn 2014). Thus, although not the main goal of our evaluation of NSM, the inclusion of a web data collection mode in the ChIRDU study represents an opportunity to learn about the benefits and costs of web network sampling in comparison with in-person and telephone modes of data collection.
} 
had been trained in interviewing techniques. Recruitment started with the selection of seven seed respondents known to the principal investigators of the project or to the four field interviewers. Seed selection featured stratification by socioeconomic status, gender, county of residence and birthplace. All seven seeds were interviewed in-person to establish rapport and to motivate them to recruit their network alters into the study. The in-person and phone sample recruitment process proceeded iteratively to recruit new waves of respondents, with the two survey modes proceeding in parallel such that referrals from each mode were interviewed by the same interviewer using the same mode.

The web survey was launched in June 2018. It was preceded by a pilot to test core content, response missingness, and usability issues. Three seed respondents known to the researchers or the field interviewers, stratified by gender and county of residence, were administered the survey in web-based form and were asked to nominate their network alters. Email survey invitation to the nominated alters selected for participation contained a unique link to a Qualtrics survey. When they clicked on the survey link, a web page opened with the informed consent, request for approval of participation, responses to eligibility questions and request to fill out the survey questionnaires in the preferred language (simplified Chinese used in mainland China, traditional Chinese used in Taiwan or Hong Kong or English). The design of the web survey provided a professional and engaging impression with the logos of the authors' institutions prominently featured on each page.

All respondents regardless of survey mode were invited to complete a series of questionnaires. An individual questionnaire captured respondents' socio-demographic characteristics, household composition, education, job and migration histories, future migration intentions, earnings, legal status, physical and psychological well-being, experiences with 
discrimination and acculturation. Upon completion of the individual questionnaire, and in compliance with the network data required by NSM, respondents were asked to complete a first network roster (Network Roster A) in which they provided minimally identifying information for six alters by answering the following question: "Please provide the first initial of the last name, the first name in Pinyin and Chinese character(s) and, where applicable, the English name of 6 people you know who were born in China, Taiwan, or Hong Kong, who are 18 or older and who reside in Durham, Orange or Wake county. These are people whose name you know and who know yours and with whom you might stop and talk at least for a moment if you ran into them on the street." This question defines the target population of our sampling approach — Chinese immigrants living in the Raleigh-Durham area. This type of question is referred to in the literature as a "name generator," which is a common and well-studied method of eliciting socially relevant peers with reasonably high levels of validity despite some biases toward nominating peers with whom respondents interact more frequently (Campbell and Lee 1991; Marin 2004; Marsden 1993; McCarty et al. 2019; Straights 2000). The name generator in Roster A was followed by name interpreter questions that is questions aimed at collecting alter attributes (gender, education, country of birth and province of origin if born in mainland China), and attributes of the relationships between the ego (respondent) and alter, with a focus on mutually exclusive relationship type (kin, friends, neighbors and coworkers) ${ }^{4}$ and strength of the tie (mode, duration and frequency of communication). Respondents were then asked to provide referral information (email, phone and/or WeChat) of each alter elicited through the name generator in Roster A. Information on alters nominated in this roster was shared globally in the NSM sampling process described in Section 1 of the Appendix. When nominated by multiple

\footnotetext{
${ }^{4}$ Interviewers were instructed to elicit the primary context of the relationship to each alter.
} 
survey modes, ties were broken by the mode that generated the nomination first. Alters with referral information who were selected by the NSM algorithm for survey participation were sent a personalized invitation by text, email or WeChat depending on the available contact information, followed by up to three reminders sent at short intervals.

In addition to Network Roster A, the ChIRDU survey collected two additional network rosters designed to represent additional social contexts of respondents' personal networks in order to explore questions on immigrant incorporation and transnationalism. These two additional networks referred to respondents' social contacts who are not within the boundaries of the population of interest to the NSM sampling process. Network Roster B elicited network alters with name generator "Please provide the first initials of three people you know who were born in the U.S. and reside in the Raleigh-Durham area”. Network Roster C elicited alters with name generator "Please provide the first initials of three Chinese people you know who reside outside of the U.S. including in your country of origin." Name interpreter questions similar to those in Network Roster A were then asked to elicit Rosters B and C alters' attributes (with current country of residence elicited for alters in Roster C so as to differentiate between transnational ties in country of origin or in another country) and attributes of the relationship with respondent.

In the in-person and phone modes, while the individual questionnaire was intervieweradministered through computer assisted interview in Qualtrics, interviewers entered the three network rosters and contact information of Roster A nominated alters on paper and pencil questionnaires in order to keep this information separate from respondent's information for confidentiality reasons. A full in-person interview lasted about 50 minutes, while a phone interview was slightly shorter. 
In the self-administered web survey, upon completion of the three network rosters, a new page opened alerting respondents to expect an email or text from the research team within 24 hours seeking referral information of the alters nominated in Roster A. In addition to this message, web respondents received up to two reminder emails to provide this information before the survey was considered closed (four weeks after the first invitation). Respondents who did not complete the survey on the first session were able to return to it later by clicking on the same link before the link would expire. A full web-interview took about 35-40 minutes to complete. The ChIRDU Study used a number of strategies designed to facilitate respondents' provision of nominations and referral information of their alters, to encourage the participation of referred alters selected for an interview, and to preserve data confidentiality and protection. These strategies are described in detail in Sections 3 and 4 of the Appendix.

[Table 1 about here]

Table 1 shows information on sample recruitment, the number of alters obtained in Rosters A, B and $\mathrm{C}$ and estimated costs per interview. The in-person and phone interviews were completed in September 2018 when the target of 200 completed interviews per mode was achieved. The pace of sample recruitment in the web mode was slower, resulting in failure to reach the target sample size. Key indicators of the feasibility of NSM are the number of nominations and referrals per respondent (Mouw and Verdery 2012). In the ChIRDU Study, referrals are a subset of nominations, as some respondents did not provide contact information for any of their nominated alters or only for a subset of them. ${ }^{5}$ High mean numbers of nominations and referrals in inperson and phone interviews were achieved primarily because of strategies in place to obtain

\footnotetext{
${ }^{5}$ Nominations without contact information are still helpful because they contribute information about the configuration of the network which improves the efficiency of the sampling algorithm.
} 
nominations and referrals and the personalized rapport with the respondents established by field interviewers. We attribute the small difference in numbers of nominations and referrals between in-person and phone interviews to difficulties in conducting long phone interviews, especially as nominations and referrals were sought from respondents at the end of the interview when respondent fatigue was an issue. The web survey encountered more challenges in getting respondents to nominate and refer alters to the study, consistent with the experience of other web-based network approaches used to recruit samples of the general population (Schonlau and Kapteyn 2014). Reasons for these challenges include: (1) Web respondents' reluctance to provide nominations due to fear of breach of privacy and concerns about length of survey. The former is not surprising at a time when Americans do not trust institutions to protect their digitized personal data (Olmstead and Smith 2017); (2) Because we lacked the resources to follow-up web non-respondents with mail or phone, there was no opportunity to build rapport and develop trust. Our detailed informed consent form containing strong assurances of data confidentiality and legitimacy of the research team revealed insufficient to alleviate respondents' concerns; (3) Because our recruitment protocol required the mode of the parent and referred respondents to be the same, the lower mean number of web nominations and referrals compared with other modes meant a slow pace of accumulation of new web nominations and a slower pace of selection of the next wave of web respondents; (4) While the fastest internet-based network sampling study, conducted in a single college during a weekend was automated (Wejnert and Heckathorn 2008), ours required researchers to implement the sampling algorithm after disambiguating Chinese names.

The cost of a completed in-person interview was the highest $(\$ 177)$, about $\$ 50$ higher than a telephone interview, while, in line with the findings of other studies (Sinclair, 
Malawaraarachchi, and Leder 2012), the cost of a self-administered web interview was considerably lower $(\$ 84)$.

\section{Results}

\section{The Network of Chinese Immigrants in the Raleigh Durham Area and their Social Ties}

Figure 1 depicts the sample network of Chinese in the Raleigh-Durham Area revealed by NSM. This graph consists of 1,982 social ties of ChIRDU respondents to 1,644 unique local Chinese alters for a total of 1,654 nodes in the network. Of these nodes, $97.58 \%$ are mapped to one giant connected component. The identifying information collected in Network Roster A (first name in Chinese characters and its transliteration, English first name, first initial of surname, gender and contact information) allowed us to connect nominations shared by multiple respondents while minimizing challenges with the disambiguation of Chinese names. Colors of the network nodes denote the different steps involved in the NSM sample recruitment process and the disposition of each nominated alter. Red squared nodes represent the 10 seed respondents, circle nodes represent nominations. Nominations include (a) those who were not selected by the NSM algorithm (white), and those who were (b) selected, referred, contacted by the study team and participated (orange), (c) selected, referred, contacted but did not respond (purple), (d) selected, referred, contacted but refused to participate (blue), (e) selected, referred, contacted but deemed ineligible after contact (black), and (f) selected and referred with invalid contact information (green). All nodes regardless of color contribute information about the configuration of the network and improve the efficiency of the NSM sampling algorithm.

[Figure 1 here] 
While Figure 1 is generate by the network data collected in Network Roster A, Table 2 provides an illustration of the information on network ties collected in all three Network Rosters, each corresponding to a different social context: local ties to other Chinese immigrants in Roster A; local ties to natives in Roster B and transnational ties to Chinese living outside the United States in Roster C. Of a respondent's ties listed in Roster C, $80 \%$ are with someone in his/her country of origin.

Panel A of Table 2 depicts a respondent's relationship with the alter. It is notable that a substantial proportion of local ties to natives are through work (0.364), particularly in comparison to local and transnational Chinese ties. The data on relationship type can be linked to the data in Panel B, which shows the frequency of communication. Although the frequency of communication is not necessarily indicative of the strength of a social tie (Brashears and Quintane 2018; Marsden and Campbell 2012; McCarty 1995), it is interesting to note that 41\% $(6.9 \%+34.1 \%)$ of the transnational ties in Panel B involve daily or weekly communication, suggesting evidence of robust connections to Chinese outside the U.S. Data on these crossborder ties are important, as some have argued that new forms of Chinese migration networks are emerging that are increasingly diverse with respect to education and geography (Chan and Koh 2017; Yin 2007). These networks are linked to the maintenance of business and career opportunities in both the U.S. and China (Grossman 2010; Wong 2005; Wong and Tan 2018), and are based on new forms of repeated, return, and circular migration (Biao 2011; Wong and Tan 2018; Yang 2013). Finally, Panel C of Table 2 shows the race/ethnicity of local ties to natives - the relative frequency and intensity of ties to particular demographic groups vis-à-vis those to other Chinese immigrants can offer clues about the broader process of social incorporation (Zhou and Liu 2016). In terms of the broader substantive focus of the ChIRDU 
study, in future analyses the data we have collected will allow us to link networks to questions about migration intentions, attitudes and outcomes related to sociocultural incorporation.

[Table 2 about here]

\section{Survey Performance by Mode}

[Table 3 about here]

Table 3 presents ChIRDU survey outcome rates by mode of interview computed from information on disposition of nominated alters in Figure 1 and following the American Association for Public Opinion Research standard definitions (2016). Response rates for the inperson and telephone modes were quite high, $72.6 \%$ and $69.4 \%$ respectively. Although finding suitable comparisons is not straightforward, and despite heightened concerns of confidentiality surrounding studies of immigration in the national political climate prevailing during data collection, our study's overall response rate falls in the upper end of the $61 \%-76 \%$ range of the main U.S. nationally representative in-person household surveys of 2014 (Williams and Brick 2018). The 2003 New Immigrant Survey, which conducted in-person interviews with a cohort of 12,500 newly admitted legal permanent residents, reached a response rate of $68.6 \%$. The response rate for the web arm of ChIRDU is only $51 \%$, lower than those achieved by the other modes. Although the difference in response rates across modes is consistent with findings that web surveys achieve on average $11 \%$ lower response rates than other survey modes (Manfreda et al. 2008), it is notable that the contact rate for the web survey is only slightly higher than the response rate revealing the challenges of effectively contacting respondents in web surveys (barring mail or phone follow-up of non-respondents). We also did not apply special efforts to distinguish ourselves from spammers, as we assumed that our affiliation with institutions of 
higher learning would provide sufficient legitimacy to our survey. Despite these limitations, our web-mode response rate is comparable or higher than those achieved by other web surveys. In fact, a highly cited meta-analysis of 49 studies that relied on 68 web surveys reports a mean response rate of 39.6\% $(\mathrm{SD}=19.6 \%)(\mathrm{Cook}$, Heath, and Thompson 2000).

\section{The Role of Peer Referral in Response Rates}

In Network Roster A, name interpreter questions elicited from respondents the attributes of alters nominated and referred to the study (e.g. gender, education) as well as attributes of the relationship with them. Referred alters selected by the NSM sampling algorithm were invited to take the survey. If they agreed to participate, they were asked to self-report on their own characteristics during the interview. With this information, it is possible to evaluate the reliability of proxy-reports by assessing consistency with self-reports. For gender and education, $97 \%$ of referred alters' self-reported gender matches their referrer's proxy reports $(\mathrm{kappa}=0.94)$ and $76 \%$ of referred alters' education matches their referrer's proxy reports $(\mathrm{kappa}=0.59)$. This high validity of proxy reports on respondents gives us confidence in the quality of referrer's proxy-reports on non-respondents, enabling an analysis of the effect of peer referral on the likelihood of survey response for an evaluation of the role of peer referral in response rates.

These data are inherently multilevel, such that respondents are clustered within referrers as it is likely that some referrers are better at "recruiting" their peers into the NSM sample than others. We use multilevel random intercept models to assess whether any attributes of the invited individual, the referrer, or any relationship-level attribute are associated with the likelihood of survey participation. These models allow us to incorporate variability between and within 
referrers and test whether referrer's characteristics such as gender and education are associated with invited alters' survey uptake.

[Table 4 about here]

Table 4 shows the log odds of taking the survey as a function of the survey mode alone (Model 1), survey mode and the characteristics of either the invited alter or the referrer (Model 2-3, survey mode, and the attributes of both invited alter and referrer (Model 4). In Model 4, the odds ratio of responding to the web survey relative to the in-person survey (base category) is $\exp ^{-1.39}=0.25,{ }^{6}$ about $75 \%$ lower $(p=0.08)$, while the odds of response when interview mode is phone are indistinguishable from the odds of response when interview mode is in-person $(\mathrm{p}=$ 0.11). The attributes of the invited alters and of the referrer are not significantly associated with the probability of response, with the exception of referrer's education. When referrers have more than college education, invited alters have lower odds of response $\left(\exp ^{-1.25}=0.29, \mathrm{p}=0.06\right)$ than when a referrer has high school or less education. As further evidence of the appropriateness of our multi-level modeling strategy, there is unexplained variation at the level of the referrer $(\mathrm{p}<0.001$ across all models) even after controlling for demographic attributes of both the invited alter and referrer.

[Table 5 about here]

Table 5 shows the log odds of taking the survey as a function of homophily on demographic attributes of the invited alter/referrer dyad (gender and education) and relationship attributes such as strength (frequency of contact) and social context of the relationship (friend, relative, coworker, neighbor) as reported by the referrer. All models control for survey mode (results not

\footnotetext{
${ }^{6}$ Since odds of response to in person survey (all else constant) are $\exp ^{3.21}=24.78$ and the odds of response to the web survey are $\exp ^{-1.39} * \exp ^{3.21}=6.17$, the odds ratio is $6.17 / 24.78=0.25$.
} 
shown), as this is a meaningful determinant of survey uptake across models. The model with the largest explanatory power is the full model (Model 7) which includes both individual and dyadlevel attributes. This model suggests that the likelihood of response is significantly associated with the similarity of the invited alter/referrer dyad and of their relationship but not with the invited alter's individual attributes. Compared to dyads with different education levels, the odds of survey response are higher when referrer and invited alter both have high school education or less with an odds ratio of $\exp ^{4.68}=107.77(\mathrm{p}<.01)$, but they are smaller when they both have college education $\left(\exp ^{0-1.51}=0.22\right)(\mathrm{p}=0.09)$. Chinese immigrants with low education may be similar across other characteristics related to the likelihood of response, while college educated individuals represent a more heterogeneous group. Frequency of communication also matters, with invited alters in dyads who rarely communicate (one or twice per year) less likely to respond than those in dyads with frequent communication (at least weekly $\mathrm{p}=0.07$ ). When referrer and invited alter are neighbors, the odds of responding to the survey are two thirds lower $\left(\exp ^{-1.12}=0.326, \mathrm{p}=0.08\right)$ than when they are friends. Overall, results of our multilevel models suggest meaningful peer effects on the likelihood of response. Peer referral is most effective if the referrer and referred alter have close ties with frequent communication or when both belong to homogenous education groups.

\section{Assessing the Representativeness of NSM samples: Comparing ChIRDU to the ACS}

To evaluate the extent to which NSM is able to generate samples for accurate population description and representation, we now turn to the comparison between key demographic characteristics of the ChIRDU sample and those of the ACS. The ACS is an annual survey that collects information on the demographic, social and housing characteristics of $1 \%$ of U.S. 
households. We restrict the ACS comparison sample to include residents of Durham, Orange and Wake counties of North Carolina, who were born in China, Taiwan or Hong Kong, were not U.S. citizens at birth, were at least 18 years old and not enrolled in school at the time of interview. We use the combined 5-year 2014-2018 ACS sample files (Ruggles et al. 2020). Comparisons of ChIRDU and ACS estimates are reported in Table 6 with means and confidence intervals grouped by mode and source. Our comparisons focus on estimating group proportions on six demographic characteristics: gender, education, age, marital status, length of time in the U.S., and U.S. citizenship. All estimates from the NSM and ACS samples are weighted. ACS estimates, standard errors and confidence intervals were estimated using the ACS person-level replication weights available in the ACS PUMS file and using the Successive Differences Replication (SDR) method described in the ACS design (Minnesota Population Center 2019). Standard errors and weights for the ChIRDU proportion estimates were computed using a bootstrap resampling approach similar to those proposed by Thompson (2020) and Gile and Handcock (2015) which rely on the topology of the observed sample network in Figure 1 to select many re-samples using the NSM sampling protocol used in the actual survey. More details on the sampling weights are provided in Section 5 of the Appendix.

After applying weights, we test differences across ChIRDU sample estimates grouped by mode, between each ChIRDU mode and ACS estimates and between all ChIRDU modes combined and ACS estimates using t-ratio tests.

[Table 6 about here]

Comparing across pairs of ChIRDU samples by mode, the comparison between in-person and phone samples (Columns 2 and 3) show the largest gaps in proportions, with proportionately more in person respondents who are younger (more in the 30-39 age category and fewer in the 
$60+$ category), more educated (fewer with just college and more with more than college),

proportionately fewer who report U.S. citizenship than in the phone sample, all tested differences with t-ratios greater than 1.96. Comparing each ChIRDU sample by mode with the ACS, there are proportionately fewer people who are $60+$ and report U.S. citizenship in the in-person sample than in the ACS (t-ratio >1.96). In the phone sample, there are proportionately more people with a college education than in the ACS and proportionately fewer with more than college education (t-ratios $>1.96)$. In the web sample, there are proportionately fewer with high school education than in the ACS (t-ratio $>1.96)$. Although this result is plausible due to the digital divide based on educational attainment and income, the web sample size is smaller than the required threshold to detect moderate differences (Appendix Section 2), hence we are underpowered to draw meaningful conclusions from the difference between the web sample and the ACS.

When all modes are combined, the gender, age and education distribution of the ChIRDU sample is strikingly close to that of the ACS, with only significantly higher proportions who are college educated in the ChIRDU sample compared with the ACS and significantly smaller proportions reporting U.S. citizenship in the ChIRDU sample. The first difference is driven by more college educated and fewer with more than college education in the phone arm of our study relative to the ACS, which could be due to misreporting of educational credentials during phone interviews. The negative sign of the ChIRDU-ACS difference for proportion U.S. citizen is consistent with studies that find higher coverage of naturalized citizens in the ACS compared with administrative data (Van Hook and Bachmeier 2013). Nonetheless, the overall comparison between ChIRDU and ACS shows striking similarity giving us confidence in the representativeness of the ChIRDU sample recruited with NSM techniques. 


\section{Discussion and Conclusions}

Immigration to the U.S. has diversified in terms of place of origin and demographic profile. Immigrants are now more spatially dispersed and the incidence of immigrants who live their economic and social lives across international borders is an important aspect of migration. Concurrent to this changing portrait of immigration, new challenges have emerged to the provision of accurate descriptions of, and meaningful comparisons across, immigrant origin groups. These groups are often too rare as a proportion of the total population and/or spatially dispersed to be sufficiently covered in standard probability sampling designs barring high screening costs required to ensure the inclusion of a minimum number of group members for analytical samples for inference. At the same time, studies of the processes of migration and immigration have highlighted the facilitating roles of migrant networks for the decision to migrate or to return home, for social integration in the receiving society, and for the maintenance of transnational ties. Yet, the measurement of social networks relevant to these processes and the reliance on networks to recruit representative samples of migrants have not been a privileged domain of large-scale surveys of migration. A recurring challenge in investigating the heterogeneous role of networks in migration has been the collection of high-quality data that measure the kin and non-kin ties between migrants and potential migrants, return-migrants and non-migrants in origin communities and with natives in destination communities. Studies that focus on small samples of respondents and their personal networks have highlighted the tradeoff between the significant costs, in terms of respondent fatigue, attrition and non-response, of personal networks that span across multiple social domains and the advantages offered by large samples with only a limited number of network indicators. 
This paper describes a network-based sampling approach (Network Sampling with Memory, NSM) which relies on social networks to recruit samples of rare populations of migrants and collects ancillary data that allow researchers to explore the role of networks in migration. We applied NSM techniques with three modes of data collection (in-person, phone, and web) to recruit and survey a sample of the rapidly growing Chinese immigrant community of North Carolina for the Chinese Immigrants in the Raleigh Durham Area study (ChIRDU), in order to illustrate the feasibility of collecting detailed network data a part of a broader migration survey, to demonstrate the role of peer referral in response rates and to test the ability of NSM to recruit a population representative sample of a rare population of immigrants in a cost-effective manner. We have demonstrated that NSM is a practical and cost-effective means of generating large-scale, population representative samples of rare immigrant groups for inference. Although obtaining contact information for link-tracing referrals can be a slow and complex process (Beauchemin and Gonzalez-Ferrer 2011) and despite well-known challenges of low response to surveys (National Research Council 2013), we show that a combination of known models of survey participation with the peer referral element of link tracing designs can yield sufficiently large numbers of nominations and referrals and high response rates to recruit a sample that accurately describes the characteristics of the population of interest when compared with the ACS. Although in the case of the ChIRDU study we deliberately chose to sample a population that was likely to have good coverage in the ACS in order to compare selected demographic measures between the two surveys as a test of NSM, future researchers might use NSM to study rare or hidden populations that either do not have good coverage in public data or where the costs involved in screening interviews makes conventional sampling techniques prohibitively expensive. 
This approach also has several advantages for the study of networks and migration. First, it directly measures migrant network characteristics. We used multiple name generators and name interpreters to elicit lists of a respondent's ties grouped according to the context of the immigration experience -- local co-ethnic ties at destination, local ties with natives at destination and global co-ethnic ties, including with the country of origin --, and the type and intensity of these interactions. In future analyses of the ChIRDU individual and network data we will explore the operations of immigrant networks in a context of immigrants' spatial dispersion, the process of social incorporation in new destinations, and the role of communication networks in sustaining transnational ties. For example, the name generator that elicits global ties is particularly suited to consider the social and economic activities of transnational Chinese migrants, especially highly educated professionals such as those who, similar to the Chinese community in Silicon Valley (Wong 2005), dominate the profile of the Chinese community in the Raleigh Durham area and contribute to the increasing geographic and educational diversity of Chinese immigration to the U.S. Second, the link-tracing nature of the NSM sample relies on minimally identifying information to generate ties across sampled and unsampled alters linked by multiple nominations across egocentric networks. Similar to other studies that have collected information on ties that extend across respondents' personal networks with alters in common (e.g. Vacca, Stacciarini and Tranmer 2019; Vacca et al. 2020), our approach allows researchers to trace out a sample of a network. This sampled network can then be completed with modelbased approaches to impute missing network ties, such as those that rely on exponential random graph models (ERGM) to reconstruct the features of the true network (Handcock and Gile 2010; Smith 2012; Gile and Handcock 2017). These approaches can, under certain conditions, provide 
valid estimates of the structural properties of the network (Smith, Morgan and Moody 2022), which can then be related to measures of immigrant incorporation.

While our present application of NSM techniques is limited to a local sample, it is possible to extend this approach to the recruitment of binational or multi-sited samples, starting from the community of origin or destination and soliciting cross-border nominations. To illustrate this point, among the three name generators used in the ChIRDU study, the one eliciting global ties captured links to migrant sending locales suggesting the feasibility of tracing links back to the area of origin from lists of contacts elicited from migrants at destination. As a second illustration, a simple snowball technique was used in the 2010 Network Survey of Immigration and Transnationalism (NSIT), which surveyed 600 members of a Mexican migrant community with network nominations that spanned three regions: the RDU area of North Carolina, Houston, Texas and Guanajuato, Mexico. The sampling started with 17 "seed" immigrants in North Carolina and Houston, relied on respondents' referrals to residents of these sites from the same origin and extended the sample to recruit network members in Guanajuato. The NSIT study demonstrated the feasibility of obtaining a large number of nominations and referrals from respondents to recruit multi-sited samples, with the significant advantage of collecting network data directly from migrants at destination linked to the community of origin (Mouw, Chavez, et al. 2014; Verdery et al. 2018). These illustrations are promising and call for further investigations of the benefits, costs and trade-offs of sampling from global networks to explore the operation of migrants' transnational ties.

The domain of NSM is not just immigrants but any networked population. NSM can have broad applicability to other rare or hard-to-survey populations connected via a social network where survey respondents are willing to answer survey questions about their networks 
and provide referrals to randomly selected network contacts. Earlier studies have successfully collected this type of network information among stigmatized populations such as methamphetamine users in New York City (Dombrowski et al. 2012) and female sex workers in China (Merli et al. 2015; Weir et al. 2012; Yamanis et al. 2013). It is also possible to maximize respondents' anonymity in network rosters, while making network matching techniques feasible using schemes to encode identifying information (e.g. Dombrowski et al. 2012).

Our work contributes to research on migrant networks and survey research on rare and hard-to-survey populations. Our evaluation of the feasibility of data collection methods which rely on peer referral and respondents' social networks is also relevant to those interested in seeking alternatives to conventional data collection schemes (Brick 2011). Response rates to government and privately sponsored household surveys for social science research have been falling throughout the world's high income countries (Czajka and Beyler 2016; De Leeuw and De Heer 2002), including the United States (National Research Council 2013) with reasons attributed to growing technological (call screening) and physical (gated entryway) barriers and a lower propensity of potential respondents to participate when contacted by researchers (Miller 2017). The costs involved with attempts to raise response rates, minimize the risk of bias in estimates, and preserve research designs are high (Curtin, Presser, and Singer 2005; National Research Council 2013). The identification of new approaches that increase respondents' motivation to participate in surveys is central to an agenda to develop better approaches to increase survey response (National Research Council 2013). Network-based approaches where the interaction between the interviewer and respondent is filtered by peer recruitment are promising, with the additional advantage that the ancillary network data collected can be used to study network-based social processes. 
Table 1. NSM Sample Recruitment, Feasibility of Network Data Collection and Cost by Survey Mode

\begin{tabular}{lccc}
\hline & In-person & Telephone & Web \\
\hline Sample Recruitment & & & \\
Target sample size & 200 & 200 & 200 \\
Time in the field & March-Sept & March-Sept & June 2018-Jan \\
Number of seeds & 2018 & 2018 & 2019 \\
Number of cases assigned to interviewer/web & $7^{(\mathrm{a})}$ & $7^{(\mathrm{a})}$ & 3 \\
Number of completed interviews (including seeds) & 274 & 291 & 159 \\
Number of partial interviews & 199 & 202 & 81 \\
Feasibility of Network Data Collection & 0 & 0 & 2 \\
Mean number of ties nominated in Roster A (SD) & & \\
Mean number of ties referred in Roster A (SD) & & & \\
Mean number of ties nominated in Roster B (SD) & $4.6(1.8)$ & $3.7(2.2)$ & $3.1(3)$ \\
Mean number of ties nominated in Roster C (SD) & $2.3(1.9)$ & $3.4(2.2)$ & $1.7(2.6)$ \\
Cost per valid interview & $2.9(0.5)$ & $2.7(0.8)$ & $1.5(1.5)$ \\
\hline
\end{tabular}

Notes: SD = Standard Deviation

(a) Seeds for in person and telephone sample were shared across the two modes.

(b) Target for number of nominated and referred ties per respondent for Roster A, B and C was 6, 3, and 3, respectively.

(c) Survey cost calculations include hourly labor costs of interviewers and web survey manager, transportation costs for in-person interviews, monetary incentives for all interview modes and programming costs of the Qualtrics survey applied equally to each interview mode. 
Table 2: Descriptive Information on Network Ties in Roster A (Local Chinese), Roster B (Local Natives) and Roster C (Chinese Outside of the U.S.)

\begin{tabular}{lcccccc}
\hline Panel A. Relationship with Alter & & & & & \\
& Co-worker & Friend & Neighbor & Relative & Other & N \\
Local Chinese & 0.099 & 0.732 & 0.058 & 0.112 & NA & 1963 \\
Local natives & 0.364 & 0.4 & 0.131 & NA & 0.105 & 1307 \\
$\begin{array}{l}\text { Chinese outside of the U.S. } \\
\text { (transnational ties) }\end{array}$ & 0.035 & 0.554 & NA & 0.368 & 0.043 & 1309
\end{tabular}

\section{Panel B. Communication Frequency}

\begin{tabular}{|c|c|c|c|c|c|}
\hline & Daily & Weekly & Monthly & $\begin{array}{c}\text { Yearly or } \\
\text { less than } \\
\text { yearly }\end{array}$ & $\mathrm{N}$ \\
\hline Local Chinese & 0.196 & 0.408 & 0.286 & 0.110 & 1963 \\
\hline Local natives & 0.348 & 0.322 & 0.197 & 0.134 & 1307 \\
\hline $\begin{array}{l}\text { Chinese outside of the U.S. } \\
\text { (transnational ties) }\end{array}$ & 0.069 & 0.341 & 0.328 & 0.262 & 1309 \\
\hline
\end{tabular}

Panel C. Race/ethnicity of alters (local natives only)

\begin{tabular}{lccccc} 
& Chinese & \multicolumn{3}{c}{$\begin{array}{c}\text { Other Asian } \\
\text { (non- }\end{array}$} \\
& Black & American & Hispanic & Chinese) & White \\
Local natives & 0.079 & 0.051 & 0.044 & 0.155 & 0.672 \\
\hline
\end{tabular}

Notes: $\mathrm{N}=$ number of ties 
Table 3. NSM Performance Indicators: Outcome Rates by Mode

\begin{tabular}{lccc}
\hline & In person & Phone & Web \\
\hline Response rate (RR1) $^{\mathrm{a}}$ & 72.6 & 69.4 & 50.9 \\
Response rate (RR2) $^{\mathrm{b}}$ & 72.6 & 69.4 & 52.2 \\
Refusal rate $^{\mathrm{c}}$ & 17.5 & 20.6 & 1.3 \\
Contact rate $^{\mathrm{d}}$ & 90.1 & 90.0 & 53.5 \\
\hline Total assigned cases & 274 & 291 & 159
\end{tabular}

Notes: Outcome rates computed according to guidelines from the American Association for Public Opinion Research (2016)

${ }^{\mathrm{a}} \mathrm{RR} 1=\mathrm{I} /((\mathrm{I}+\mathrm{P})+(\mathrm{R}+\mathrm{NC}+\mathrm{O}))$

${ }^{\mathrm{b}} \mathrm{RR} 2=(\mathrm{I}+\mathrm{P}) /((\mathrm{I}+\mathrm{P})+(\mathrm{R}+\mathrm{NC}+\mathrm{O}))$

${ }^{\mathrm{c}}$ Refusal Rate $1=\mathrm{R} /((\mathrm{I}+\mathrm{P})+(\mathrm{R}+\mathrm{NC}+\mathrm{O}))$

${ }^{\mathrm{d}}$ Contact Rate $1=(\mathrm{I}+\mathrm{P})+\mathrm{R}+\mathrm{O} /((\mathrm{I}+\mathrm{P})+\mathrm{R}+\mathrm{O}+\mathrm{NC})$

where I is completed interview, $\mathrm{P}$ is partial interview, $\mathrm{R}$ is known refusal, $\mathrm{NC}$ is Non-Contact (someone referred by a parent respondent and selected by the NSM algorithm who failed to respond to the research team's invitation after 4 attempts to contact) and $\mathrm{O}$ is Other (alter's invalid referral information provided by the parent respondent) 
Table 4: Random Effects Response Models: Log Odds Ratios of Response by Attributes of the Invited Alter and the Referrer

\begin{tabular}{|c|c|c|c|c|}
\hline & $(1)$ & $(2)$ & $(3)$ & $(4)$ \\
\hline \multicolumn{5}{|c|}{ Invited alter's mode (ref. = in-person) } \\
\hline \multirow[t]{2}{*}{ Phone } & 0.71 & 1.30 & 0.71 & 1.29 \\
\hline & $(0.71)$ & $(0.81)$ & $(0.71)$ & $(0.81)$ \\
\hline \multirow[t]{2}{*}{ Web } & $-1.29 \dagger$ & $-1.40 \dagger$ & $-1.29 \dagger$ & $-1.39 \dagger$ \\
\hline & $(0.76)$ & $(0.78)$ & $(0.76)$ & $(0.78)$ \\
\hline \multicolumn{5}{|c|}{ Invited alter's gender (ref.= male) } \\
\hline \multirow[t]{2}{*}{ Female } & & 0.05 & & 0.05 \\
\hline & & $(0.31)$ & & $(0.31)$ \\
\hline \multicolumn{5}{|c|}{ Invited alter's education (ref. = HS or less) } \\
\hline \multirow[t]{2}{*}{ College } & & 0.03 & & 0.08 \\
\hline & & $(0.86)$ & & $(0.89)$ \\
\hline \multirow[t]{2}{*}{ More than college } & & 0.81 & & 0.87 \\
\hline & & $(0.87)$ & & $(0.90)$ \\
\hline \multicolumn{5}{|c|}{ Referrer's gender (ref. = male) } \\
\hline \multirow[t]{2}{*}{ Female } & & & -0.21 & -0.36 \\
\hline & & & $(0.31)$ & $(0.33)$ \\
\hline \multicolumn{5}{|c|}{ Referrer's education (ref. $=$ HS or less) } \\
\hline \multirow[t]{2}{*}{ College } & & & -0.31 & -0.80 \\
\hline & & & $(0.54)$ & $(0.63)$ \\
\hline \multirow[t]{2}{*}{ More than college } & & & -0.29 & $-1.25 \dagger$ \\
\hline & & & $(0.51)$ & $(0.65)$ \\
\hline \multirow[t]{2}{*}{ Constant } & $2.27 * * *$ & $2.03 *$ & $2.67 * * *$ & $3.21 * * *$ \\
\hline & $(0.39)$ & $(0.81)$ & $(0.64)$ & $(0.79)$ \\
\hline \multirow{2}{*}{$\begin{array}{l}\text { Referrer level } \\
\text { variance }\end{array}$} & $13.62 * * *$ & $17.35 * * *$ & $13.60 * * *$ & $17.16^{* * *}$ \\
\hline & $(3.17)$ & $(4.90)$ & $(3.15)$ & $(4.78)$ \\
\hline \multirow{2}{*}{$\begin{array}{l}\text { Pseudo R2 } \\
\text { BIC }\end{array}$} & 0.32 & 0.35 & 0.32 & 0.34 \\
\hline & 3660.60 & 3375.34 & 3680.79 & 3393.63 \\
\hline \multirow{2}{*}{$\begin{array}{l}\mathrm{N} \\
\text { Notes: Standard err } \\
\text { using McFadden's } \\
\text { null (intercept only) } \\
\dagger \mathrm{p}<.10 ; * \mathrm{p}<.05\end{array}$} & 916 & 898 & 916 & 898 \\
\hline & $\begin{array}{l}\text { re shown in } \\
\text { lo-R2 whic } \\
\text { lel. BIC is } \\
<.01 ; * * * \text { p }\end{array}$ & $\begin{array}{l}\text { oarentheses } \\
\text { compares } \\
\text { ayesian Inf } \\
.001 \text { (two }\end{array}$ & $\begin{array}{l}\text { Pseudo R2 } \\
\text { e given mo } \\
\text { cmation Cri } \\
\text { ailed tests) }\end{array}$ & $\begin{array}{l}\text { alculated } \\
\text { el to the } \\
\text { rion. }\end{array}$ \\
\hline
\end{tabular}


Table 5: Random Effects Response Models: Log Odds Ratios of Response by Attributes of the Invited Alter and of the Referrer-Invited Dyad

$\begin{array}{llllll}(1) & (2) & (3) & (4) & \text { (5) } & \text { (6) }\end{array}$

\begin{tabular}{|c|c|c|c|c|}
\hline \multicolumn{5}{|c|}{$\begin{array}{l}\text { Relationship attribute: Gender of referrer and invited alter (ref. = different } \\
\text { genders) }\end{array}$} \\
\hline Both female & $\begin{array}{c}0.00 \\
(0.43)\end{array}$ & $\begin{array}{c}0.29 \\
(0.43)\end{array}$ & $\begin{array}{c}0.35 \\
(0.44)\end{array}$ & $\begin{array}{c}0.09 \\
(0.66)\end{array}$ \\
\hline Both male & $\begin{array}{c}0.39 \\
(0.32)\end{array}$ & $\begin{array}{c}0.32 \\
(0.36)\end{array}$ & $\begin{array}{c}0.32 \\
(0.39)\end{array}$ & $\begin{array}{c}0.53 \\
(0.67)\end{array}$ \\
\hline
\end{tabular}

Relationship attribute: Education of referrer and invited alter (ref. = different education)

$\begin{array}{lcccc}\text { Both HS or less } & 3.96^{* *} & 4.14^{* *} & 3.64 * * & 4.68^{* *} \\ \text { Both College } & (1.35) & (1.44) & (1.39) & (1.46) \\ & -0.58 & -0.62 & -0.72 & -1.51 \dagger \\ \text { Both more than college } & (0.71) & (0.72) & (0.73) & (0.90) \\ & 0.80 \dagger & 0.79 \dagger & 0.73 \dagger & 0.32 \\ & (0.42) & (0.43) & (0.43) & (0.75)\end{array}$

Relationship attribute: Frequency of contact (ref. = at least weekly)

$\begin{array}{lccc}\text { Monthly } & -1.06^{*} & -0.80 & -0.63 \\ & (0.47) & (0.51) & (0.53) \\ 1-2 \text { times a year } & -0.77 \dagger & -0.92 \dagger & -0.94 \dagger \\ & (0.43) & (0.51) & (0.52)\end{array}$

Relationship attribute: Type (ref. $=$ friend)

Relative

$\begin{array}{lll}0.45 & -0.26 \quad-0.27\end{array}$

$\begin{array}{lll}(0.58) & (0.70) \quad(0.69)\end{array}$

Co-worker

$\begin{array}{lll}0.55 & 0.25 & 0.31\end{array}$

Neighbor

$\begin{array}{lll}(0.59) & (0.60) \quad(0.60)\end{array}$

$-1.44^{*} \quad-1.49 * \quad-1.12 \dagger$

$(0.62) \quad(0.63) \quad(0.64)$

Invited alter's gender (ref. $=$ male)

Female

Invited alter's education (ref. $=$ HS or less)

College

More than college

\begin{tabular}{lccccccc}
\hline Constant & $\begin{array}{c}2.26^{* * *} \\
(0.43)\end{array}$ & $\begin{array}{c}2.15^{* * *} \\
(0.47)\end{array}$ & $\begin{array}{c}2.02^{* * *} \\
(0.49)\end{array}$ & $\begin{array}{c}2.95^{* * *} \\
(0.49)\end{array}$ & $\begin{array}{c}2.42^{* * *} \\
(0.42)\end{array}$ & $\begin{array}{c}2.91^{* * *} \\
(0.58)\end{array}$ & $\begin{array}{c}1.86 \dagger \\
(0.99)\end{array}$ \\
\hline Alter Mode Control & Yes & Yes & Yes & Yes & Yes & Yes & Yes \\
\hline Referrer level & $14.27^{* * *}$ & $15.54^{* * *}$ & $16.45^{* * *}$ & $13.36^{* * *}$ & $14.28^{* * *}$ & $16.88^{* * *}$ & $21.75^{* *}$ \\
Variance & $(3.36)$ & $(3.72)$ & $(4.03)$ & $(3.00)$ & $(3.39)$ & $(4.28)$ & $(7.09)$ \\
\hline Pseudo R2 & 0.33 & 0.33 & 0.34 & 0.32 & 0.33 & 0.34 & 0.36 \\
$\mathrm{BIC}$ & 3592.91 & 3603.06 & 3533.93 & 3628.72 & 3618.62 & 3502.07 & 3300.19 \\
\hline $\mathrm{N}$ & 907 & 916 & 907 & 913 & 910 & 905 & 890 \\
\hline
\end{tabular}


Notes: Standard errors are shown in parentheses. Estimates calculated using the ChIRDU sampling weights. Pseudo R2 calculated using McFadden's pseudo-R2 which compares the given model to the null (intercept only) model. BIC is Bayesian Information Criterion.

$\dagger \mathrm{p}<.10 ; * \mathrm{p}<.05 ; * * \mathrm{p}<.01 ; * * * \mathrm{p}<.001$ (two-tailed tests) 
Figure 1. Social Network of Chinese Immigrants in the Raleigh-Durham Area by survey outcome

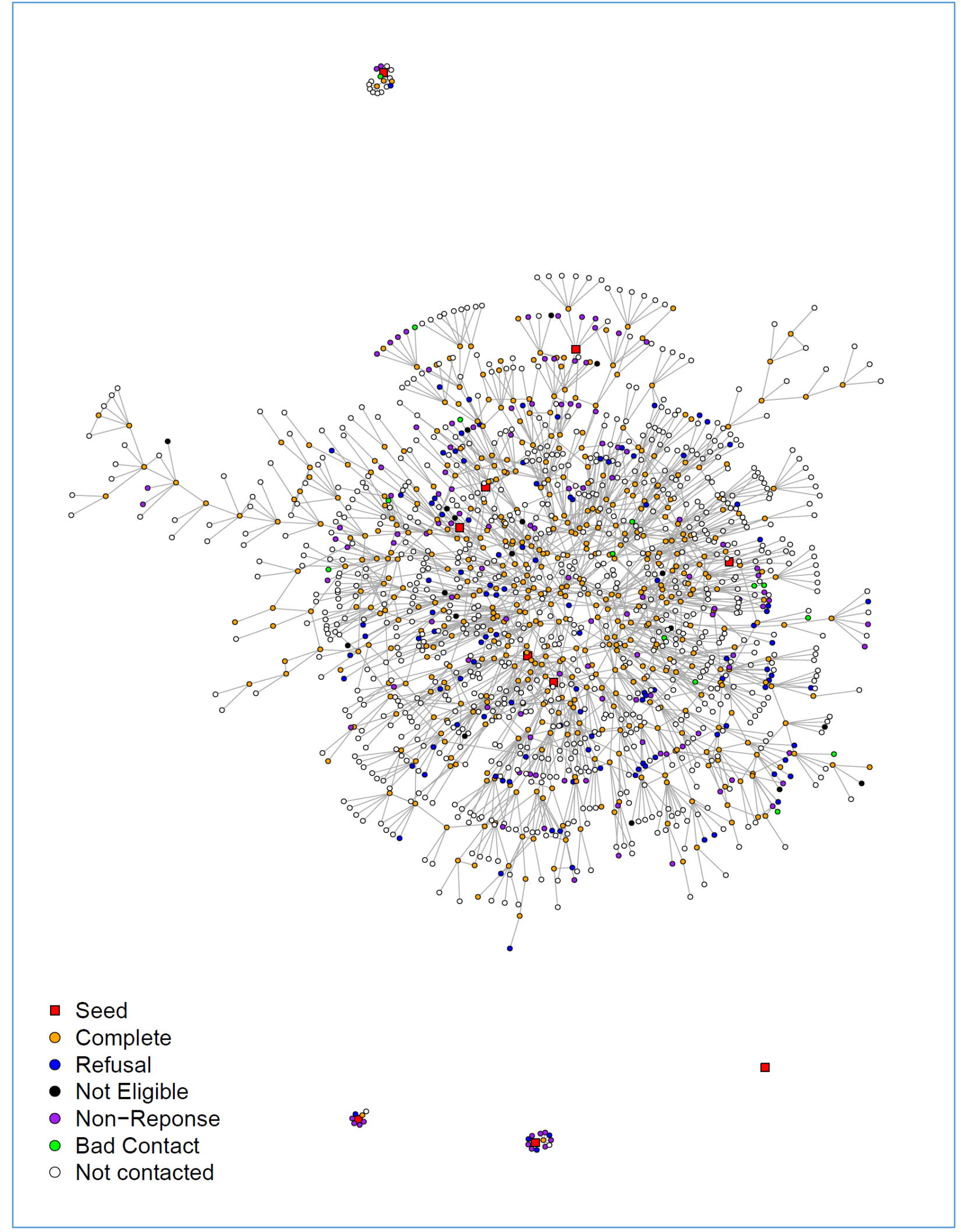




\section{References}

American Association for Public Opinion Research. 2016. "Standard Definitions, 9th Edition." in Final Dispositions of Case Codes and Outcome Rates for Surveys. AAPOR.

Baizan, P., and A. Gonzalez-Ferrer. 2016. "What Drives Senegalese Migration to Europe? The Role of Economic Restructuring, Labor Demand, and the Multiplier Effect of Networks.” Demographic Research 35(1):339-80.

Bashi, Vilna. 2007. Survival of the Knitted: Immigrant Social Networks in a Stratified World. Stanford, Calif.: Stanford, Calif. : Stanford University Press, 2007.

Beauchemin, C. 2015. "Migration between Africa and Europe (MAFE): Looking beyond Immigration to Understand International Migration.” Population-E 70(1):7-12.

Beauchemin, C. 2018. Migration between Africa and Europe. 2018: Springer.

Beauchemin, Cris. 2014. “A Manifesto for Quantitative Multi-Sited Approaches to International Migration.” International Migration Review 48(4):921-38.

Biao, Xiang. 2011. “A Ritual Economy of 'Talent': China and Overseas Chinese Professionals.” Journal of Ethnic and Migration Studies 37(5):821-38.

Biernacki, P., and D. Waldorf. 1981. "Snowball Sampling. Problems and Techniques of Chain Referral Sampling.” Sociological Methods and Ressearch 10:141-63.

Billsborrow, Richard. 2016. “Concepts, Definitions and Data Collection Approaches.” Pp. 109_ 56 in International Handbook of Migration and Population Distribution. Dordrecht Heidelberg New York London: Springer.

Boyd, M. 1989. "Family and Personal Networks in International Migration: Recent Developments and New Agendas.” International Migration Review 23:638-70.

Boyd, Monica. 1989. "Family and Personal Networks in International Migration: Recent Developments and New Agendas." International Migration Review 23(3):638-70. 
Brashears, Matthew E., and Eric Quintane. 2018. “The Weakness of Tie Strength.” Social Networks 55:104-15.

Brick, J. Michael. 2011. “The Future of Survey Sampling.” Public Opinion Quarterly 75(5 SPEC. ISSUE):872-88.

Caballero, M. E., B. C. Cadena, and B. K. Kovak. 2018. "Measuring Geographic Migration Patterns Using Matrículas Consulares.” Demography 55(3):1119-45.

Campbell, K. E., and B. A. Lee. 1991. "Name Generators in Surveys of Personal Networks." Social Networks 13:203.

Cesare, N., H. Lee, T. McCormick, E. Spiro, and E. Zagheni. 2018. "Promises and Pitfalls of Using Digital Traces for Demographic Research.” Demography 55(5):1979-99.

Chan, Yuk Wah, and Sin Yee Koh. 2017. New Chinese Migrations: Mobility, Home, and Inspirations.

Côté, R. R., J. E. Jensen, L. M. Roth, and S. M. Way. 2015. “The Effects of Gendered Social Capital on U.S. Migration: A Comparison of Four Latin American Countries." Demography 52(3):989-1015.

Cook, C., F. Heath, and R. L. Thompson. 2000. "A Meta-Analysis of Response Rates in Web- or Internet-Based Surveys." Educational and Psychological Measurement 60:821-36.

Curran, S. R., F. Garip, C. Y. Chung, and K. Tangchonlatip. 2005. "Gendered Migrant Social Capital: Evidence from Thailand." Social Forces 84:225-255.

Curran, S. R., and E. Rivero-Fuentes. 2003. "Engendering Migrant Networks: The Case of Mexican Migration.” Demography 40(2):289-307.

Curtin, R., S. Presser, and E. Singer. 2005. "Changes in Telephone Survey Nonresponse over the Past Quarter Century.” Public Opinion Quarterly 69(1):87-98. 
Czajka, John L., and Amy Beyler. 2016. "Declining Response Rates in Federal Surveys: Trends and Implications." Mathematica Policy Research Background Paper 15.

Davis, B., G. Stecklov, and P. Winter. 2002. "Domestic and International Migration from Rural Mexico: Disaggregating the Effects of Network Structure and Composition.” Population Studies 56:291-309.

de Haas, Hein. 2010. "The Internal Dynamics of Migration Processes: A Theoretical Inquiry." Journal of Ethnic and Migration Studies 36(10):1587-1617.

de Leeuw, E. D., and W. de Heer. 2002. “Trends in Household Survey Nonresponse: A Longitudinal and International Comparison.” Pp. 41-54 in Survey Nonresponse, edited by J. L. E. R.M. Groves D.A. Dillman and R. J. A. Little. New York: Wiley.

Dillman, D. A., J. D. Smyth, and L. M. Christian. 2009. Internet, Mail, and Mixed-Mode Surveys: The Tailored Design Method (3rd Ed.). 3rd ed. Hoboken: John Wiley \& Sons. Dolfin, Sarah, and Garance Genicot. 2010. "What Do Networks Do? The Role of Networks on Migration and 'Coyote' Use.” Review of Development Economics 14(2):343-59.

Dombrowski, Kirk, Bilal Khan, Travis Wendel, Katherine McLean, Evan Misshula, and Ric Curtis. 2012. "Estimating the Size of the Methamphetamine-Using Population in New York City Using Network Sampling Techniques.” Advances in Applied Sociology 2:204-45.

Donato, Katharine M., Jonathan Hiskey, Jorge Durand, and Douglas S. Massey. 2010. "Migration in the Americas: México and Latin America in Comparative Context." The ANNALS of the American Academy of Social and Political Science 630(1):6-17.

Durand, Jorge, Douglas S. Massey, and René M. Zenteno. 2001. "Mexican Immigration to the United States: Continuities and Changes.” Latin American Research Review 36(1):107-27.

Elo, I. E. Frankenberg, R. Gansey, and D. Thomas. 2015. "Africans in the American Labor 
Market.” Demography 52(5):1513-42.

Fawcett, J. T., and F. Arnold. 1987. "The Role of Surveys in the Study of International Migration: An Appraisal.” The International Migration Review 21(4):1523-40.

Fawcett, James T. 1989. "Networks, Linkages, and Migration Systems." International Migration Review 23(3):671-80.

Flippen, Chenoa, and Eunbi Kim. 2015. "Immigrant Context and Opportunity: New Destinations and Socioeconomic Attainment among Asians in the United States." The ANNALS of the American Academy of Political and Social Science 660(1):175-98.

Fussell, Elizabeth, and Douglas S. Massey. 2004. "The Limits to Cumulative Causation: International Migration from Mexican Urban Areas.” Demography 41(1):151-171.

Garip, F. 2008. "Social Capital and Migration: How Do Similar Resources Lead to Divergent Outcomes?" Demography 45(3):591-617.

Garip, F. 2012. "Discovering Diverse Mechanisms of Migration: The Mexico-U.S. Stream from 1970 to 2000." Population and Development Review 38(3):393-433.

Garip, F. 2016. “On the Move: Changing Mechanisms of Mexico-US Migration.”

Garip, F., and A. L. Asad. 2016. "Network Effects in Mexico U.S. Migration: Disentangling the Underlying Social Mechanisms.” American Behavioral Scientist 60(10):1168-93.

Gile, Krista J., and Mark S. Handcock. 2010. "Respondent-Driven Sampling: An Assessment of Current Methodology." Sociological Methodology 40(1):285-327.

Gile, Krista J., and Mark S. Handcock. 2015. "Network Model-Assisted Inference from Respondent-Driven Sampling Data." Journal of the Royal Statistical Society. Series A: Statistics in Society 178(3):619-39.

Gile, Krista J. and Mark S. Handcock. 2017. "Analysis of Networks with Missing Data with 
Application to the National Longitudinal Study of Adolescent Health." Journal of the Royal Statistical Society. Series C: Applied Statistics 66(3):501-519.

Goel, Sharad, and Matthew J. Salganik. 2010. “Assessing Respondent-Driven Sampling.” Proceedings of the National Academy of Science 107(15):6743-47.

Gold, Steven J. 2005. "Migrant Networks: A Summary and Critique of Relational Approaches to International Migration.” The Blackwell Companion to Social Inequalities 257-85.

Grossman, Martin. 2010. “Business Networks, 'Brain Circulation', and the American Chinese Diaspora." VINE 40(3):287-300.

Groves, Robert M., Robert B. Cialdini, and Mick P. Couper. 1992. “Understanding the Decision to Participate in a Survey." Public Opinion Quarterly 56(4):475-95.

Groves, Robert M., Stanley Presser, and Sarah Dipko. 2004. “The Role of Topic Interest in Survey Participation Decisions.” Public Opinion Quarterly 68(1):2-31.

Groves, Robert M., Eleanor Singer, and Amy Corning. 2000. "Leverage-Saliency Theory of Survey Participation: Description and an Illustration.” Public Opinion Quarterly 64(3):299_ 308.

Guarnizo, Luis Eduardo, Arturo Ignacio Sanchez, and Elizabeth M. Roach. 1999. “Mistrust, Fragmented Solidarity, and Transnational Migration: Colombians in New York City and Los Angeles.” Ethnic and Racial Studies 22(2):367-96.

Hagan, Jacqueline Maria. 1998. "Social Networks, Gender, and Immigrant Incorporation: Resources and Constraints.” American Sociological Review 55-67.

Handcock, M. S. and Gile, K. J. 2010. "Modeling networks from sampled data." Ann. Appl. Statist., 4, 5-25.

Haug, Sonja. 2008. "Migration Networks and Migration Decision-Making." Journal of Ethnic 
and Migration Studies 34(4):585-605.

Heckathorn, Douglas D. 1997. "Respondent-Driven Sampling: A New Approach to the Study of Hidden Populations." Social Problems 44(2):174-99.

Heckathorn, Douglas D. 2002. "Respondent-Driven Sampling II: Deriving Valid Population Estimates from Chain-Referral Samples of Hidden Populations." Social Problems 49(1):1134.

Hill, Katherine Michelle. 2018. "Sweet and Sour: Social Networks and Inequality in a Chinese Restaurant." Sociology of Race and Ethnicity 4(1):114-27.

Hoang, Kimberly Kay. 2015. "Nailing Race and Labor Relations: Vietnamese Nail Salons in Majority-Minority Neighborhoods." Journal of Asian American Studies 18(2):113-39.

Jampaklay, A., K. Korinek, and B. Entwisle. 2007. "Residential Clustering among Nang Rong Migrants in Urban Settings of Thailand." Asian and Pacific Migration Journal 16(4):485510.

Korinek, K., B. Entwisle, and A. Jampaklay. 2005. "Through Thick and Thin: Layers of Social Ties and Urban Settlement among Thai Migrants.” American Sociological Review 70(5):779-800.

Krissman, Fred. 2005. “Sin Cayote Ni Patrón: Why the ‘Migrant Network’ Fails to Explain International Migration.” International Migration Review 39(1):4-44.

Lancee, Bram. 2012. Immigrant Performance in the Labour Market : Bonding and Bridging Social Capital. Amsterdam: Amsterdam University Press.

Lee, Hang Young. 2015. "Network Disadvantages of Immigrants: Social Capital as a Source of Immigrant Disadvantages in the Labor Market." Duke University.

Lee, Jennifer, and Samuel Kye. 2016. "Racialized Assimilation of Asian Americans.” Annual 
Review of Sociology 42:253-73.

Lee, Jennifer, and M. Zhou. 2015. The Asian \{A\}merican Achievement Paradox. Russell Sage Foundation.

Levitt, P., and N. Glick Schiller. 2004. "Conceptualizing Simultaneity: A Transnational Social Field Perspective on Society.” International Migration Review 38(3):1002-1039.

Liang, Z., and H. Morooka. 2004. "Recent Trends of Emigration from China: 1982-2000." International Migration 42(3):145-64.

Liu, Mao-Mei. 2013. "Migrant Networks and International Migration: Testing Weak Ties." Demography 50:1243-77.

Lubbers, M. J., A. M. Verdery, and J. L. Molina. 2020. “Social Networks and Transnational Social Fields: A Review of Quantitative and Mixed-Methods Approaches.” International Migration Review 54(1):177-204.

Lubbers, Miranda J., José Luis Molina, Jürgen Lerner, Ulrik Brandes, Javier Ávila, and Christopher McCarty. 2010. "Longitudinal Analysis of Personal Networks. The Case of Argentinean Migrants in Spain.” Social Networks 32(1):91-104.

MacDonald, J. S., and L. D. MacDonald. 1964. "Chain Migration, Ethnic Neighborhood Formation and Social Networks." The Milbank Memorial Fund Quarterly 42:82-97.

Manfreda, K. L., J. Berzelak, V. Vehovar, M. Bosnjak, and I. Haas. 2008. “Web Surveys versus Other Survey Modes: A Meta-Analysis Comparing Response Rates." International Journal of Market Research 50:79-104.

Marin, A. 2004. "Are Respondents More Likely to List Alters with Certain Characteristics?: Implications for Name Generator Data." Social Networks 26(4):289-307.

Marsden, P. V. 1993. "The Reliability of Network Density and Composition Measures." Social 
Networks 15(399-421).

Marsden, Peter V., and Karen E. Campbell. 2012. "Reflections on Conceptualizing and Measuring Tie Strength.” Social Forces 91(1):17-23.

Massey, D. S. 1988. "Economic Development and International Migration in Comparative Perspective." Population \& Development Review 14(3):383-413.

Massey, D. S. 1990. "Social Structure, Household Strategies, and the Cumulative Causation of Migration." Population Index 56:3-26.

Massey, Douglas S., Rafael Alarcon, Jorge Durand, and Humberto Gonzalez. 1987. Return to Aztlan: The Social Process of International Migration from Western Mexico. Berkeley and Los Angeles: University of California Press.

Massey, Douglas S., Joaquin Arango, Graeme Hugo, Ali Kouaouci, Adela Pellegrino, and J. Edward Taylor. 1993. "Theories of International Migration: A Review and Appraisal.” Population and Development Review 431-66.

Massey, Douglas S., Joaquin Arango, Graeme Hugo, Ali Kouaouci, Adela Pellegrino, and J. Edward Taylor. 1994. “An Evaluation of International Migration Theory: The North American Case." Population and Development Review 699-751.

Massey, Douglas S., and Maria Aysa-Lastra. 2011. "Social Capital and International Migration from Latin America." International Journal of Population Research.

Massey, Douglas S., and Kristin Espinosa. 1997. "What's Driving Mexico-US Migration? A Theoretical, Empirical, and Policy Analysis.” American Journal of Sociology 102:939-999. Massey, Douglas S., and Felipe García-España. 1987. “The Social Process of International Migration." Science 237:733-738.

Massey, Douglas S., Luin Goldring, and Jorge Durand. 1994. "Continuities in Transnational 
Migration: An Analysis of Nineteen Mexican Communities.” American Journal of Sociology 99:1492-1533.

Massey, Douglas S., and Rene Zenteno. 1999. “The Dynamics of Mass Migration.” Proceedings of the National Academy of Sciences 96:5328-5335.

McCarty, Christopher. 1996. “The Meaning of Knowing as a Network Tie.” Connections 18:2031.

McCarty, Christopher, Miranda J. Lubbers, Raffaele Vacca, and Jose Luis Molina. 2019. Conducting Personal Network Research. A Practical Guide. New York and London: The Guildford Press.

McCreesh, N., S. Frost, J. Seeley, J. Katongole, M. N. Tarsh, R. Ndunguse, F. Jichi, N. L. Lunel, D. Maher, L. G. Johnston, and P. Sonnenberg. 2012. "Evaluation of Respondent-Driven Sampling." Epidemiology (Cambridge, Mass 23(1):138.

Menjivar, Cecilia. 2000. Fragmented Ties: Salvadoran Immigrant Networks in America. Univ of California Press.

Merli, M. Giovanna Merli, James Moody, Jeffrey Smith, Jing Li, Sharon Weir, and Xiangsheng Chen. 2015. "Challenges to Recruiting Representative Samples of Female Sex Workers in China Using Respondent Driven Sampling.” Social Science \& Medicine 125:79-93.

Merli, M. Giovanna, Ashton Verdery, Ted Mouw, and Jing Li. 2016. "Sampling Migrants from Their Social Networks: The Demography and Social Organization of Chinese Migrants in Dar Es Salaam, Tanzania.” Migration Studies 4(2):182-214.

Miller, Peter V. 2017. “Is There a Future for Surveys?” Public Opinion Quarterly 81(S1):20512.

Mountz, A., and R. A. Wright. 1996. "Daily Life in the Transnational Migrant Community of 
San Agustin, Oaxaca, and Poughkeepsie, New York.” Diaspora: A Journal of Transnational Studies 5(3):403-28.

Mouw, Ted, Sergio Chavez, Heather Edelblute, and Ashton Verdery. 2014. "Binational Social Networks and Assimilation: A Test of the Importance of Transnationalism.” Social Problems 61(3):329-59.

Mouw, Ted, Ashton Verdery, Giovanna Merli, Jing Li and Jennifer Shen. 2014. Sampling a Hidden Population without a Sampling Frame. A Practical Application of Network Sampling with Memory. Presented at the 2014 Population Association of America Meetings. Mouw, Ted, and Ashton M. Verdery. 2012. "Network Sampling with Memory: A Proposal for More Efficient Sampling from Social Networks." Sociological Methodology 42(1):206-56.

Mowen, John. C. and Robert B. Cialdini. 1980. "On Implementing the Door-in-the-Face Compliance Technique in a Business Context." Journal of Marketing Research 17(2): 253258.

Munshi, Kaivan. 2020. “Social Networks and Migration.” Annual Review of Economics 12:50324.

National Academy of Sciences Engineering and Medicine. 2015. "Chapter 5: Spatial Dimensions of Immigrant Integration.” Pp. 207-45 in The Integration of Immigrants into American Society. Washington, D.C.: The National Academies Press.

National Research Council. 2013. Nonresponse in Social Science Surveys: A Research Agenda. Washington, D.C.: National Academies Press.

Nee, Victor, Jimy M. Sanders, and Scott Sernau. 1994. "Job Transitions in an Immigrant Metropolis: Ethnic Boundaries and the Mixed Economy." American Sociological Review 59(6):849-72. 
Olmstead, K., and A. Smith. 2017. Americans and Cybersecurity. Washington, D.C.: Pew Research Center.

Palloni, A., D. S. Massey, M. Ceballos, K. Espinosa, and M. Spittel. 2001. "Social Capital and International Migration: A Test Using Information on Family Networks.” American Journal of Sociology 106(5):1262-98.

Parrado Emilio A, Chris McQuiston, and Chenoa Flippen. 2005. Participatory Survey Research: Integrating Community Collaboration and Quantitative Methods for the Study of Gender and HIV Risks among Hispanic Migrants. Sociological Methods and Research 34:204-239.

Pew Research Center. 2013. https://www.pewresearch.org/wpcontent/uploads/sites/3/2013/04/Asian-Americans-new-full-report-04-2013.pdf

Pew Research Center. 2017. https://www.pewresearch.org/hispanic/2017/12/07/rise-in-u-simmigrants-from-el-salvador-guatemala-and-honduras-outpaces-growth-from-elsewhere/

Pew Research Center 2020 https://www.pewresearch.org/fact-tank/2020/08/20/key-findingsabout-u-s-immigrants/

Portes, Alejandro. 1998. "Social Capital: Its Origins and Applications in Modern Sociology." Annual Review of Sociology 24:1-24.

Rindfuss, Ronald R., Aree Jampaklay, Barbara Entwisle, Yothin Sawangdee, Katherine Faust and Pramote Prasartkul. 1994. The Collection and Analusis of Social Network Data in Nan Rong, Thailand. Pp. in Martina Morris, ed. Network Epidemiology: A Handbook for Survey Design and Data Collection. Oxford University Press Scholarship Online.

Riosmena, Fernando, and Douglas S. Massey. 2012. "Pathways to El Norte: Origins, Destinations, and Characteristics of Mexican Migrants to the United States 1." International Migration Review 46(1):3-36. 
Ruggles, Steven, Sarah Flood, Ronald Goeken, Josiah Grover, Erin Meyer, Jose Pacas, and Matthew Sobek. 2020. “IPUMS USA: Version 10.0 [Dataset].” Minneapolis, MN: IPUMS 2020.

Ryan, Louise. 2011. “Migrants' Social Networks and Weak Ties: Accessing Resources and Constructing Relationships Post-Migration.” The Sociological Review 59(4):707-24.

Ryan, Louise, Rosemary Sales, Mary Tilki, and Bernadetta Siara. 2008. "Social Networks, Social Support and Social Capital: The Experiences of Recent Polish Migrants in London." Sociology 42(4):672-90.

Sakamoto, A., C. Kim, and I. Takei. 2013. "Moving out of the Margins and into the Mainstream The Demographics of Asian Americans in the New South.” Pp. 132-64 in Asians in Dixie : Race and Migration in the South. University of Illinois Press: J. Desai and K.Y.Yoshi. Salganik, Matthew J., and Douglas D. Heckathorn. 2004. "Sampling and Estimation in Hidden Populations Using Respondent-Driven Sampling.” Sociological Methodology 34(1):193240.

Schonlau, M. B. Wedmer, and A. Kapteyn. 2014. "Recruiting an Internet Panel Using Respondent-Driven Sampling.” Journal of Official Statistics 30(3):291-310.

Sinclair, M. J. O’Toole, M. Malawaraarachchi, and K. Leder. 2012. “Comparison of Response Rates and Cost-Effectiveness for a Community-Based Survey: Postal, Internet and Telephone Modes with Generic or Personalised Recruitment Approaches.” BMC Medical Research Methodology 2012:12-132.

Small, M. L. 2009. 'How Many Cases Do I Need?' On Science and the Logic of Case Selection in Field-Based Research.” Ethnography 10(1):5-38.

Smith, Jeffrey A. 2012. "Macrostructure from Microstructure: Generating Whole Systems from 
Ego Networks." Sociological Methodology 42:155-205.

Smith, Jeffrey A., James Moody and Jonathan H. Morgan. 2017. "Network sampling coverage II: The effect of non-random missing data on network measurement." Social Networks 48: 7899.

Spiller, M. W., K. J. Gile, M. S. Handcock, C. M. Mar, and C. Wejnert. 2018. "Evaluating Variance Estimators for Respondent-Driven Sampling." Journal of Survey Statistics and Methodology 6(1):23-45.

Straights, B. 2000. “Ego’s Important Discussants or Significant People: An Experiment in Varying the Wording of Personal Network Name Generators." Social Networks 22(2):12340.

Sudman, S., and G. Kalton. 1986. "New Developments in the Sampling of Special Populations." Annual Review of Sociology 12:401-29.

Taylor, J. E. 1986. "Differential Migration, Networks, Information and Risk." Research in Human Capital and Development 4:147-71.

Taylor, J. E. 1987. "Undocumented Mexico-US Migration and the Returns to Households in Rural Mexico." American Journal of Agricultural Economics 69:626-38.

Taylor, J. E., S. Rozelle, and A. de Brauw. 2003. "Migration and Incomes in Source Communities: A New Economics of Migration Perspective from China." Economic Development and Cultural Change 52:75-101.

Thompson, Steve. 2020. New estimates for network sampling. arXiv:2002.01350v1 [stat.ME] 2 Feb 2020.

Tilly, Charles, and C. Harold Brown. 1967. "On Uprooting, Kinship, and the Auspices of Migration." International Journal of Comparative Sociology 8(2):139-64. 
Tippett, R. 2018. Fast-Growing Asian Population Highly Concentrated in NC Urban Areas.

Toma, S. 2016. "The Role of Migrant Networks in the Labour Market Outcomes of Senegalese Men: How Destination Contexts Matter.” Ethnic and Racial Studies 39(4):593-613.

Toma, Sorana, and Sophie Vause. 2014. "Gender Differences in the Role of Migrant Networks: Comparing Congolese and Senegalese Migration Flows." International Migration Review 48(4):972-97.

Vacca, R., Jeanne-Marie R. Stacciarini, and Mark Tranmer. 2019. Cross-classified Multi-level Models for Personal Networks: Detecting and accounting for Overlapping Actors. Sociological Methods and Research.

Vacca, Raffaele, Giacomo Solano, Miranda Jessica Lubbers, José Luis Molina, and Christopher McCarty. 2020. "A Personal Network Approach to the Study of Immigrant Structural Assimilation and Transnationalism." Social Networks 53(1):72-89.

Van Hook, J. and J. D. Bachmeier. How well does the American Community Survey count naturalized citizens? Demographic Research 29(1):1-32.

Van Hook, Jennifer, Frank D. Bean, James D. Bachmeier, and Catherine Tucker. 2014. "Recent Trends in Coverage of the Mexican-Born Population of the United States: Results From Applying Multiple Methods Across Time.” Demography 51(2):699-726.

Verdery, Ashton M., Ted Mouw, Heather Edelblute, and Sergio Chavez. 2018. "Communication Flows and the Durability of a Transnational Social Field." Social Networks 53:57-71.

Verdery, Ashton, M. Giovanna Merli, James Moody, Jeffrey Smith, and Jacob Fisher. 2015. “Assessment of Multiple Respondent Driven Sampling Estimators under Real and Ideal Recruitment Conditions in an Empirical Population of Female Sex Workers in China." Epidemiology 26(5):661-65. 
Volz, Erik, and Douglas D. Heckathorn. 2008. "Probability-Based Estimation Theory for Respondent Driven Sampling.” Journal of Official Statistics 24(1):79-97.

Waldinger, Roger. 2013. Immigrant Transnationalism. Current Sociology Review 61(5-6) 756777.

Weir, Sharon S., M. Giovanna Merli, Jing Li, Anisha D. Gandhi, William W. Neely, Jessie K. Edwards, Chirayath M. Suchindran, Gail E. Henderson, and Xiang Sheng Chen. 2012. "A Comparison of Respondent-Driven and Venue-Based Sampling of Female Sex Workers in Liuzhou, China." Sexually Transmitted Infections 88 Suppl 2.

Wejnert, C. 2009. “An Empirical Test of Respondent-Driven Sampling: Point Estimates, Variance, Degree Measures, and Out-of-Equilibrium Data." Sociological Methodology 39(1):73-116.

Wejnert, C., and D. Heckathorn. 2008. "Web-Based Network Sampling: Efficiency and Efficacy of Respondent-Driven Sampling for Online Research." Sociological Methods \& Research $37: 105-34$.

Wejnert, C., H. Pham, N. Krishna, B. Le, and E. DiNenno. 2012. "Estimating Design Effect and Calculating Sample Size for Respondent-Driven Sampling Studies of Injection Drug Users in the United States." AIDS and Behavior 16(4):797-806.

Williams, Douglas, and J. Michael Brick. 2018. “Trends in U.S. Face-To-Face Household Survey Nonresponse and Level of Effort." Journal of Survey Statistics and Methodology 6(2):186-211.

Wong, B., and Tan, C.-B., editors. 2018. China's Rise and the Chinese Overseas. London and New York: Routledge.

Wong, Bernard P. 2005. “The Chinese in Silicon Valley: Globalization, Social Networks, and 
Ethnic Identity.” Lanham, MD.

Yamanis, Nina, M. Giovanna Merli, W. Whipple Neely, Felicia F. Tian, James Moody, Xiaowen Tu, and Ersheng Gao. 2013. "An Empirical Analysis of the Impact of Recruitment Patterns on RDS Estimates among a Socially Ordered Population of Female Sex Workers.” Sociological Methods and Research 42(3):392-425.

Yang, P. Q. 2013. "From Sojourning to Settlement to Transnationalism: Transformations of the Chinese Immigrant Community in America." Pp. 122-40 in Routledge handbook of the Chinese diaspora, edited by C.-B. Tan. New York: Routledge.

Yin, Xia Huang. 2007. “Diverse and Transnational: Chinese (PRC) Immigrants in the United States." Journal of Chinese Overseas 3(1):122-45.

Zhao, Y. 2003. "The Role of Migrant Networks in Labor Migration: The Case of China." Contemporary Economic Policy 21(4):500-511.

Zhou, Min, and Hong Liu. 2016. "Homeland Engagement and Host-Society Integration: A Comparative Study of New Chinese Immigrants in the United States and Singapore.” International Journal of Comparative Sociology 57(1-2):30-52. 